JOSÉ ANTONIO CRESPO

\title{
El pensamiento de Francisco I. Madero y la oposición democrática contemporánea
}

"Lo que deseamos por lo pronto es que se cumpla la ley".

Francisco I. Madero.

$\mathbf{E}$

L SISTEMA POLÍTICO MEXICANO atraviesa por una crisis de legitimidad, sobre todo a partir de fines del sexenio pasado, cuando se evidenció el fracaso del modelo de desarrollo económico iniciado en la década de los cuarentas. El nivel de corrupción alcanzado por la administración lopezportillista, por otro lado, contribuyó a intensificar el desgaste de la credibilidad en el gobierno por parte de numerosos grupos de la ciudadanía, principalmente de la clase media y del sector empresarial. Esto ha dado lugar al resurgimiento de un movimiento ciudadano en demanda de democratización del proceso político. No es un movimiento propiamente partidista, aunque evidentemente que en él participan los partidos de oposición independiente, interesados en contender en la arena electoral sobre una base de igualdad frente al partido oficial. Sin embargo, toman parte también grupos e individuos no identificados con algún partido político, sino miembros de diversas organizaciones civiles; académicos, periodistas, líderes de grupos independientes, comerciantes, profesionistas liberales, etc.

No se trata ciertamente de un grupo homogéneo, pero tiene en común la convicción de que en los momentos difíciles por los que pasa el país, el respeto a la Constitución, es decir, de las prácticas genuinamente democráticas que ella establece, se hace indispehsable para recobrar la confianza 
de la ciudadanía en su gobierno y en la Nación, y que de no llevarse a cabo, nuevos problemas surgirán a nivel social y político que agravarán la situación presente. Incluso quienes consideran a la democracia. política como un elemento de menor importancia en relación a la justicia social, como son numerosos miembros de la izquierda política y social, en general aceptan que la democracia política puede ser un instrumento importante para la consecusión de otras metas.

La demanda por democracia política no es nueva en nuestra historia, evidentemente. Sin embargo, hay momentos en los que aquélla cobra mayor ímpetu e intensidad; momentos en los que la legitimidad de un régimen determinado baja a un nivel mínimo, como en los años anteriores a la revolución de Ayutla, o a la revolución mexicana. La crisis de legitimidad por la que atraviesa el régimen priísta se intensificó a fines del sexenio pasado, en parte por el quiebre del modelo de desarrollo económico, pues a partir de Alemán éste servía como su principal fuente de legitimación, ya que los ideales de democracia política y justicia social proclamados por la revolución de 1910, habían quedado postergados indefinidamente, para concentrarse en la industrialización. Cuando quedó claro que ésta se vería obstaculizada gravemente, la exigencia de democracia política volvió a cobrar fuerza en la oposición formal y la disidencia. Al mismo tiempo, ha surgido en los medios académicos y periodísticos un debate sobre las posibilidades de la democracia, sus obstáculos, los actores pertinentes y la forma en que podría darse la transición, en caso de darse. Los puntos más importantes de ese debate han sido analizados con detalle en otra parte. ${ }^{1}$ Pero en todo caso puede decirse que responde también al ambiente predominante en la ciudadanía, de agotamiento y fastidio por las prácticas claramente autoritarias llevadas a cabo por el partido oficial en los procesos políticos del país.

No por casualidad, muchos de los argumentos que utiliza la oposición democrática de nuestros días en contra del

1 Crespo, José Antonio, "México: la crisis de legitimidad y el debate sobre la democracia (1982-1985)". Ponencia presentada en el II Foro de Coyuntura, UIA, mayo de 1986 . 
régimen priísta, son sumamente parecidos a los manejados por la oposición a finales del Porfiriato. Esto puede verse con claridad a través del pensamiento de Francisco I. Madero, en su fase legalista, cuyos elementos principales se encuentran resumidos, desde luego, en su obra más importante, aparecida en Coahuila en $1908^{2}$ con motivo de las elecciones presidenciales de 1910 . No era por supuesto la primera vez que se denunciaba al régimen de Díaz, pero la crítica de esos momentos reflejaba la decadencia y el agotamiento del régimen, así como su falta de credibilidad y legitimidad frente a la ciudadanía. Ello nos sugiere la existencia de un gran paralelismo entre el pensamiento opositor de Madero, y la crítica que ahora hace la oposición democrática al régimen priísta, así como las demandas que se le formulan. Al menos eso se tratará de comprobar en este trabajo. No es desde luego la primera vez que se sugiere alguna similitud entre el Porfiriato y el régimen prísta. ${ }^{3}$ Pero por ahora nos interesa establecer esa similitud a partir de las críticas expresadas por la oposición en uno y otro régimen, pues algo nos pueden decir acerca de las características de ambos, en un momento en el que atraviesan por una franca crisis de legitimidad.

\section{El régimen: Pax porfírica y Pax priista}

La oposición democrática de nuestros días caracteriza al sistema político mexicano como un autoritarismo de partido, que guarda las formas democráticas y pretende respetar la Constitución de 1917, pero que pasa por alto esas disposiciones y centraliza el poder en una cúspide desde donde fluyen las decisiones. Los candidatos no son elegidos por elecciones libres, sino que son impuestos desde arriba, a partir de lealtades políticas e intereses de los círculos priístas. Se asegura, por supuesto, la formalidad electoral para proporcionar a este proceso un aire de legitimidad demo-

2 La sucesión presidencial en 1910, México, Ed. Offset, 1985.

${ }^{3}$ Cfr. Meyer, Lorenzo, "Continuidades e innovaciones en la vida política mexicana del siglo XX; el antiguo y el nuevo régimen". Foro Internacional No. 61, julio-septiembre, 1975 . 
crática. Igualmente, la división de poderes establecida constitucionalmente se mantiene sólo en la forma, pero en realidad el poder se concentra de manera casi aboluta en el Poder Ejecutivo, dando así lugar a lo que se ha denominado "Presidencialismo Mexicano". La oposición democrática desmiente la retórica oficial en el sentido de que el sistema político mexicano va democratizándose, gradual pero continuamente. Más bien sostiene que el sistema ha logrado consolidarse como un autoritarismo institucional, es decir, que ejerce la dominación a través de instituciones de masas, y que sólo guarda la formalidad democrática.

La crítica maderista al Porfiriato es en esencia la misma; la de haber subvertido el orden constitucional establecido en 1857, sustituyendo la democracia política por un autoritarismo personalista, aunque eso sí, preocupado por mantener la imagen democrática. No sólo atacaba Madero el reeleccionismo sino que el sufragio no fuera respetado por el gobierno para imponer a los candidatos oficiales. Tanto para Madero como para la oposición democrática contemporánea, la democracia política se ve como fundamental para resolver los problemas nacionales, evitando el abuso de poder y permitiendo a la ciudadanía intervenir de alguna forma en el proceso político. Tanto uno como otros reconocen que el régimen ha logrado la paz social y la estabilidad política durante un largo periodo, lo cual es visto como saludable para el país, en términos generales. Pero no habiendo las libertades políticas básicas ni los instrumentos necesarios para evitar el abuso del poder, esa paz, dice Madero, se convierte en "la paz sepulcral de los pueblos oprimidos".4

En todo caso, Madero consideraba que la estabilidad impuesta por Díaz podría ser de gran utilidad como fase preparativa para la madurez política de los mexicanos. Dice, en este sentido:

La obra del generál Díaz ha consistido en borrar los odios profundos que antes dividían a los mexicanos y en asegurar la paz por más de 30 años, que aunque mecánica al princi-

${ }^{4}$ Op. cit., p. 39. 
pio ha llegado a echar profundas raíces en el suelo nacional, al grado que su florecimeinto en nuestro país parece asegurarla.

El general Díaz con su mano de hierro ha acabado con nuestro espíritu turbulento e inquieto y ahora que tenemos la calma necesaria y que comprendemos cuán deseable es el reino de la ley, ahora sí estamos aptos para concurrir pacíficamente a las urnas electorales para depositar nuestro voto. ${ }^{5}$

De manera semejante, la oposición actual puede aceptar el beneficio relativo que ha representado la estabilidad política derivada de la institucionalización del sistema mexicano, sobre todo en comparación con muchos de los paises latinoamericanos. De hecho, es éste uno de los elementos básicos sobre los que el PRI reclama legitimidad, lo mismo que hacían los porfiristas. Pero la oposición insiste en que la estabilidad sin democracia tiene sólo un valor relativo, y que aún aceptando que el autoritarismo hubiera sido necesario en algún momento para pacificar al país, no es indispensable prolongarlo indefinidamente. Tal parece ser el sentido del lema de campaña de Acción Nacional: "Ya es tiempo".

Con respecto a los argumentos utilizados por algunos porfiristas de que el pueblo no se encontraba preparado para la democracia, se asemeja a la sostenido por algunos priístas entre bambalinas, y tanto Madero como la oposición actual mantienen que no se puede tomar ello como una razón que justifique la centralización del poder. Madero, en particular, responde que:

...se ha calumniado al pueblo mexicano al decir que no está apto para la democracia, [...] quien no lo está es el actual gobierno, cuyo poder dimana de la fuerza, y que por consiguiente considera a ésta como la ley suprema. ${ }^{6}$

Así, la acusación expresa de que no hay democracia porque el sistema no lo permite, aparece también en las

5 Ibid., p. 262.

6 Ibid., p. 275. 
críticas que se hacen al régimen actual. Se insiste asimismo, que bajo ciertas condiciones institucionales la democracia política no tiene por qué no funcionar. ${ }^{7}$

Desde luego no se debe pasar por alto aquí el hecho de que el régimen actual es mucho más flexible, y con mayor capacidad de canalizar la movilización política de amplios sectores que el régimen porfirista, debido a que el primero es un autoritarismo institucional, como ya se dijo, mientras que el segundo representa un autoritarismo de tipo personalista. Por lo mismo, el régimen actual goza de más fuerza y continuidad que cuaıquier autoritarismo personalista (como el de Franco, Pinochet, Somoza, Marcos, etc.). Precisamente Madero temía que el autoritarismo impuesto por Díaz lograra institucionalizarse, en buena medida a través de la designación como sucesor por parte del dictador "al que mejor pueda seguir su misma política, con lo cual quedará establecido de un modo definitivo el régimen de poder absoluto".$^{8}$ En efecto, uno de los elementos claves de la institucionalización política, aunque no el único, es precisamente el del traspaso pacífico del poder, dentro del mismo grupo si se trata de un régimen autoritario, o de un grupo a otro en caso de hablarse de un sistema democrático. Por ello, Madero consideraba que antes de que tal práctica se instituyera, la ciudadanía debía organizarse para presentar una lucha pacífica en pro de la democracia, pues de no surgir ésta, numerosos males caerían sobre la Nación. Decía:

Al implantarse entre nosotros de un modo definitivo el régimen de poder absoluto, nunca podremos prever qué conductas observarán nuestros mandatarios, pues no teniendo compromiso alguno con la Nación, sólo se guiarán por los impulsos de sus pasiones y no reconocerán más ley que sus deseos personales. Con este motivo, nuestra decadencia será segura. ${ }^{9}$

7 Cfr. Krauze, Enrique, "Por una democracia sin adjetivos". Vuelta No. 86. Enero de 1984.

8 op. cit., p. 314.

9 Ibid., p. 305. 
La demanda por democracia en Madero, entonces, tenía su racionalidad política; no se expresaba sólo en términos legales o morales, sino que era vista como un medio indispensable para alcanzar los objetivos nacionales.

De igual forma, la oposición democrática del presente formula su demanda en términos racionales. No habla ya de prevenir la institucionalización del autoritarismo, como hacía Madero, pues esto es un hecho ya desde hace tiempo. Incluso más de uno afirmaría sin titubear que los temores de Madero se cumplieron precisamente al consolidarse la institucionalización del régimen post-revolucionario. Pero en todo caso la demanda actual por democracia tiene también su propia racionalidad. La de proporcionar un resorte fundamental para la recuperación de la Nación y evitar en lo futuro los abusos y desaciertos de la élite política, que hemos testificado desde años atrás. ${ }^{10}$ Un cambio profundo ciertamente, al menos en lo que hace a lo político, de la misma magntitud que el que Madero exigía a Díaz. Pero un cambio que sólo requiere del apego de los gobernantes a la Constitución; no una subversión del orden legal, sino su estricta observancia.

\section{La élite política}

En un régimen autoritario, sea personalista, sea institucionalizado, quienes se encuentran cerca del poder, y en alguna medida se benefician de él, responden en general hacia sus jefes y superiores, y no tanto a la ciudadanía. Estando bien con las altas jerarquías pueden pasar por alto los ordenamientos legales, y por tanto abusar del poder, en la medida en que su posición y jerarquía se los permita. Quien está en la cúspide de la pirámide política, sea un monarca, dictador o presidente, responde sólo ante sí mismo, y dispone por lo mismo de un amplio margen para ejercer el poder de manera arbitraria y poco responsable. La doctrina democrática precisamente establece una serie de mecanismos para evitar en lo posible un ejercicio abusivo e irresponsable del poder. Ése es el mal que veía Madero en el régimen

10 Cfr. Meyer, Lorenzo, "La democracia política: esperando a Godot". Ne$x o s$ No. 100, abril de 1986. 
porfirista y que deseaba remediar a través de la democracia. Otro tanto hacen quienes ahora pugnan por la misma.

Madero reconocía que el presidente Díaz era en muchos aspectos un hombre ejemplar, y que había hecho un uso diligente del poder absoluto que disfrutaba:

En lo particular, estimo al general Díaz, y no puedo menos de considerar con respeto al hombre que fue de los que más se distinguieron en la defensa del suelo patrio, y que después de disfrutar por más de treinta años el más absoluto de los poderes, haya usado de él con tanta moderación; acontecimientos de los que muy pocos registra la Historia. ${ }^{11}$

Aún más, reconocía la honradez con la que Díaz había llevado su largo mandato. "Como adminstrador siempre ha sido íntegro, de lo cual dio una prueba brillante cuando entregó al señor Juárez $\$ 300000.00$ que tenía como sobrante en la caja del cuerpo de su ejército". ${ }^{12}$ De ello dio también prueba al abandonar el país posteriormente. Para Madero eso representaba un rasgo notable en un dictador, y se felicitaba de que, gracias a ello, "...no está a tal punto perdida la dignidad nacional". ${ }^{13}$

Difícilmente podría la oposición contemporánea expresarse en los mismos términos respecto de quienes han ocupado la silla presidencial de un tiempo a esta parte.

Pero de cualquier manera el que ello suceda así es imputable al régimen autoritario, cuyas características permiten la corrupción e impunidad de los funcionarios. Si Díaz no cayó en la deshonestidad se debe a sus rasgos personales, pues el sistema le proporcionaba el campo abierto para el enriquecimiento desmesurado.

Sin embargo, Madero sí acusaba a Don Porfirio de un profundo apego al poder, y de que no dudaba en incurrir en actos anticonstitucionales, $\mathrm{e}$ incluso al asesinato y la represión, para conservarse en él. La institucionalización del régimen priísta no permite ahora la reelección presidencial, pero en términos de los intereses del partido oficial como grupo, se recurre a procedimientos sumamente parecidos a

\footnotetext{
11 Op. cit., p. 34.

12 Ibid., p. 111.

is Ibid, p. 112.
} 
los practicados por los porfiristas. Por ello la oposición habla de "dictadura de partido", y acusa a éste de echar mano de cualquier recurso para preservar el poder en casi todos los niveles; es la política de "Carro Completo" continuamente denunciada por la oposición democrática.

Por otro lado, Madero no desconocía que muchos de los funcionarios del porfiriato sí incurrían en el manejo ilícito de los fondos públicos, y de nuevo culpaba al autoritarismo de ello.

En las esferas del gobierno predomina la corrupción administrativa, pues aunque el general Díaz y sus consejeros son honrados, no pueden por sí solos saber todo lo que pasa en la República, y ni siquiera cerca de ellos, pues es bien sabido que entre las personas que los rodean se cometen grandes abusos; ya sea especulando con los secretos de Estado, ya por medio de concesiones ventajosas para ellos [...] Gozan además de una impunidad relativa, y están muy engreídos con el actual ré $e_{j}$ imen r.e cosas. ${ }^{14}$

De la misma manera, los demócratas de nuestros días centran en la corrupción de los funcionarios públicos uno de sus ataques más asiduos en contra del régimen, tanto más cuanto que ésta se practica de manera habitual y cotidiana, y con un grado muy alto de impunidad. De nueva cuenta, el remedio más probable contra ella se propone a través de la vigilancia de la ciudadanía sobre los gobernantes, por medio de instituciones genuinamente democráticas.

El problema de una corrupción tan generalizada en el sector público es que, además del daño económico que provoca en la Nación, su práctica tiende a extenderse a otras organizaciones de la sociedad civil pues, como Madero reconocía, “...los pueblos son siempre influidos por el ejemplo de los de arriba". ${ }^{15}$

Tanto Madero como la oposición de hoy, denuncian en la élite política de sus respectivos regímenes la falta de compromiso público, así como el fingimiento en el desempeño de su cargo, y la demagogia. "Por costumbre -dice Madero- vulneran la ley; sus más solemnes protestas las

14 Ibid., p. 221.

15 Ibid., p. 218. 
ven como fórmulas vanas". ${ }^{16} \mathrm{El}$ reclutamiento de este tipo de hombres se debe básicamente, según los demócratas, a las características del régimen autoritario, pues el ascenso político y burocrático depende en estos regímenes fundamentalmente de la sumisión y servilismo a los superiores. Los hombres más íntegros, por lo general, no aceptan esas condiciones impuestas por el sistema, por lo que no pueden permanecer en él durante mucho tiempo, o bien quedan estancados en niveles inferiores del aparato burocrátco. No obstante, sostiene la corriente democrática, son estos hombres los que con mayor responsabilidad podrían llevar las riendas del gobierno, si el sistema les permitiera foguearse políticamente y llegar a los puestos del poder. Si el pueblo decidiera, dicen, habría mayor posibilidad de su ascenso al poder. Igualmente, sostiene Madero que:

Indudablemente que existen esos hombres de mérito, pero ni los conocemos, ni ellos mismos han tenido tiempo de forjarse en las candentes luchas de la idea, en el vasto campo de la democracia. ${ }^{17}$

Es éste, pues, el problema del reclutamiento y formación de líderes políticos y funcionarios, que los sistemas autoritarios no permiten resolver de acuerdo a las necesidades de la mayoría y que, de acuerdo con los demócratas, sólo a través de los procesos democráticos puede realizarse con mayor probabilidad de éxito. Ello lo afirmaba la oposición al porfiriato lo mismo que ahora lo hace la oposición al régimen priísta.

\section{El modelo de desarrollo}

Otro punto de aproximación entre el pensamiento de Madero y el de la oposición contemporánea se encuentra en la visión que uno y otros presentan acerca del modelo de desarrollo seguido por los regímenes de sus respectivas épocas. En ambos casos se reconoce el carácter modernizador o desarrollista del régimen, y se acepta que ello constituye un

16 Ibid.

17 Ibid. 
elemento fundamental de su aceptación por parte de la ciudadanía, al menos durante algún tiempo. En el caso del régimen priísta, después de consolidar el poder sobre bases autoritarias, se avocó a la tarea de impulsar de manera decisiva la industrialización del país. Se dejó de lado el programa democrático de la Revolución y se postergó indefinidamente la meta de la justicia social, para concentrarse en el desarrollo económico a través de la economía mixta, con participación de capital extranjero. ${ }^{18}$

El régimen porfirista había seguido una política similar. La pacificación lograda por Díaz había permitido al fin iniciar el proceso de industrialización pugnado tanto por liberales como conservadores. Madero reconocía éxitos logrados por el porfiriato en esta rama:

Lo único que sustenta la administración del general Díaz en su apoyo, es nuestro progreso material. Los diarios oficiosos publican estadísticas y más estadísticas demostrando que el aumento en nuestro comercio es fabuloso, que las fuentes de riqueza pública y privada han aumentado considerablemente, que nuestra red ferrocarrilera se extiende más y más, que en los puertos se construyen magníficas obras para hacerlas más accesibles a los buques de gran calado, que en todas las grandes ciudades se ha hecho el drenaje, la pavimentación de las calles, se han construido magníficos edificios, etc. ${ }^{19}$

No obstante, el hecho de poner en marcha un proyecto de desarrollo económico sin tomar en cuenta el principio de justicia social, o más bien postergándolo como una meta posterior, genera la oposición de diversos sectores, entre los que destacan desde luego los de orientación izquierdista. En el régimen de Díaz, esta crítica fue enarbolada principalmente por el Partido Liberal Mexicano, pero Madero, cuya principal preocupación era indudablemente la democracia política, no dejó de oponerse a los privilegios asociados al proyecto de modernización económica del porfiriato. Denuncia Madero, por ejemplo, que la política proteccionista a las nuevas industrias y las exenciones fiscales a las

18 Cfr. Meyer, "La democracia política...", op. cit:

19. Op. cit., p. 205. 
mismas, habían sido decretadas por Díaz tomando en cuenta “...los intereses especiales de personas o corporaciones amigas a quienes desea proteger, sin consultar los grandes intereses de la Nación, que no tiene ningún representante legítimo en esas discusiones". ${ }^{20}$ Además, el hecho de que en un país con tantos recursos, parte de su población se viera obligada a emigrar fuera del país en busca de empleo, representaba para Madero la prueba de que el desarrollo económico había venido dándose con beneficio desigual para los diversos sectores sociales. De ahí surgió parte del programa obrero y campesino propuesto por el movimiento maderista. En una obra posterior, y menos divulgada que la Sucesión Presidencial, Madero ofrecía que el nuevo gobierno democrático se ocuparía de mejorar la situación de los obreros mediante una legislación adecuada y la de los campesinos a través del reparto de los grandes latifundios. ${ }^{21}$ Así, sostenía Madero que un programa de desarrollo inequitativo perdía su sentido social. "¿De qué nos sirve nuestro portentoso progreso material - se preguntaba-, si no tenemos asegurado ni siquiera el sustento honrado de nuestras clases desvalidas?" 22

No se trata de que Madero propusiera una revolución social, sino que consideraba que el autoritarismo tiende a la política de privilegios, violando el compromiso constitucional de gobernar para toda la Nación. Por ello veía en un sistema democrático genuino la condición para llevar a cabo un mayor grado de justicia social.

Por otra parte, el modelo de desarrollo regido por el régimen priísta ha sido atacado por sus disidentes en relación a la política agropecuaria, en particular por no haber dado suficiente atención $\lambda$ ese sector como base para una industrialización sólida, sino que se le ha utilizado negligentemente para transferir recursos a la rama industrial, además de haber seguido allí también una política de privilegios.

20 Ibid., p. 209.

21 El Partido Nacional Antirreleccionista y la próxima lucha electoral. Citado por Mancicidor, José, en Historia de la Revolución Mexicana, México, Costa Amic, 1970, p. 92.

${ }_{22}$ La sucesión..., op. cit., p. 220. 
Madero hacía una crítica semejante al modelo porfirista. Al referirse al sector agropecuario, denunciaba:

En este ramo tan importante de la riqueza pública poco ha hecho el gobierno para su desarrollo, pues con el régimen de gobierno de uno solo, resulta que los únicos que se aprovechan de todas las concesiones son los que lo rodean [...] El resultado de esta política ha sido que el país, a pesar de su vasta extensión de tierras laborables, no produce ni el algodón, ni el trigo necesario para su consumo en años normales, y en años estériles, tenemos que importar hasta el maíz y el frijol, que son la base de la alimentación del pueblo mexicano. ${ }^{23}$

La forma de financiamiento del desarrollo económico ha sido, asimismo, otro punto de ataque por parte de la oposición, sobre todo en los últimos años en que la deuda pública externa rebasó las posibilidades de pago por parte del país, y se ha constituido como el principal obstáculo para continuar el crecimiento económico de manera sólida. Se dice que la política económica de López Portillo, desde sus inicios, era vista por algunos observadores como sumamente riesgosa y poco adecuada para el país. Y así lo hicieron saber. Pero la prepotencia de nuestros gobernantes no les permitió escuchar a la disidencia, a la cual calificó en esa ocasión de apocalíptica y alarmista. ${ }^{24}$ Madero pronunció también una denuncia con respecto al crédito externo como fuente de financiamento. La prosperidad debida al proyecto de Díaz, decía, se tradujo en un aumento del crédito en el extranjero, del cual hizo el dictador un uso abusivo "...hasta el grado de que ahora gravita sobre la Nación una deuda enorme". ${ }^{25}$ No obstante Madero señalaba que:

La inmensa deuda contraida por la administración actual, ha servido para desarrollar considerablemente nuestra riqueza, y no creemos que sea una gran carga para la Nación,

${ }^{23}$ Op. cit. de 1985 .

${ }^{24}$ Cfr. Paz, Octavio, "Hora cumplida. (1929-1985)". Vuelta No. 103, junio

${ }^{25}$ La sucesión..., of. cit., p. 137. 
desde el momento que con desahogo se pagan sus intereses y se va amortiguando parte de ella. ${ }^{26}$

En efecto, el problema actual de la deuda pública no tiene parangón en nuestra historia, y si Madero no vio la deuda como un problema grave, hoy día la oposición no puede sino reclamar al régimen que ella advirtió los posibles efectos de un endeudamien to desmedido, que el gobierno lopezportillista nunca reconoció como peligrosos.

Finalmente, y ante la evidencia del quiebre del modelo de desarrollo económico, la oposición democrática denuncia la ineficiencia de la élite política en la conducción del proyecto económico y en el manejo del aparato administrativo, y de nuevo la atribuye a la falta de responsabilidad pública propia del sistema autoritario. Corrupción, nepotismo, compadrazgo e impunidad son males que pueden ser mitigados, según la oposición contemporánea, a través de la democracia política, y que en gran medida han sido responsables del fracaso económico del país. Madero, sin desconocer los logros del modelo porfirista de desarrollo, también suponía que a través de las prácticas democráticas la eficiencia y la racionalidad económica y administrativa tendrían más posiblidades de prevalecer en el proceso de modernización económica.

Si en vez de un gobierno absoluto, lo hubiéramos tenido democrático, quizá nuestro progreso material hubiera sido superior, pues no hubiera habido tanto despilfarro en los estados, y si bien es cierto que los gobernadores no estarían tan ricos, en cambio las obras materiales hubieran recibido mayor impulso... ${ }^{27}$

En todo caso, el tono de la crítica formulada por Madero al modelo de desarrollo seguido por Díaz, nos recuerda al que se ha hecho en nuestros días al modelo puesto en marcha por el régimen priísta, aunque la denuncia a éste último es más acertada, pues desde la óptica actual, el fracaso 
del mismo ha sido poco menos que rotundo y las posibilidades de recuperación no se ven todavía claras.

Voluntad, de la élite política para emprender la democratización

El régimen priísta logró con su programa de industrialización crear una base de legitimidad que difícilmente podía obtener a través de las otras metas de la Revolución; la democracia política y la justicia social, ya que después del cardenismo quedaba claro que éstas habían quedado congeladas, al menos de momento. Era ésta una legitimidad por desempeño que venía a sustituir la legitimidad por principios, sobre la cual se había erigido el régimen revolucionario. Al final del sexenio lopezportillista, como se dijo, el fracaso del modelo de desarrollo vino a generar una crisis de legitimidad, pues ahora ni las metas económias podían seguir proporcionando tal legitimidad. En un intento por compensar esta situación, el gobierno de Miguel de la Madrid ofreció desde sus inicios una serie de renovaciones en el sector público; mayor honestidad en la administración pública y limpieza en los procesos electorales, fundamentalmente. Ello dio pie al resurgimiento de un debate sobre las posibilidades reales de democratización del sistema político. Este debate, como ya se dijo, está asociado al movimiento que exige la democracia política en nuestro país, por lo que tiene un aspecto de exhortación y demanda al régimen actual en ese sentido, y otro más propiamente analítico respecto de cómo se puede llevar a cabo dicho proceso.

También el libro de Madero presenta estos dos aspectos, además de los elementos críticos señalados antes. Contiene una fuerte exhortación a Díaz para que comprendiera la necesidad y conveniencia de aceptar la democracia y también era un llamado a la ciudadanía para que se organizara y exigiera la reforma democrática. Además presenta un análisis acerca de cómo podría llevarse a cabo el proceso, muy parecido al que se encuentra en el debate contemporáneo. Por supuesto que en ese debate no hay un punto de vista homogéneo, pero muchos de los elementos en que hay ma- 
yor coincidencia se asemejan a los que Madero expuso en su época, como veremos.

Un primer punto considerado como vital en el debate se centra en la voluntad política de la élite gubernamental, o la falta de ella, para impulsar desde arriba la democratización auténtica del sistema político. Este aspecto es fundamental, pues en un sistema autoritario el poder de decisión se concentra en la élite política, de allí fluye hacia abajo. Mientras el sistema tiene fuerza suficiente, la élite puede detener y ahogar cualquier iniciativa que no goce de sus simpatías y la de hacer reformas que minen o limiten su poder por lo general representa una de ellas. De cualquier forma, en un autoritarismo presidencialista, como era el de Díaz y es el priísta, la cabeza del gobierno puede en un momento dado tomar decisiones que serán acatadas por el resto de la élite, en condiciones normales. $\mathrm{Y}$ por ello se plantea la posiblidad de que el Presidente de la República pueda comprender la conveniencia de iniciar y apoyar la reforma desde arriba, en un acto considerado por los demócratas como responsable y patriótico.

En el debate de nuestros días, ha sido el historiador Enrique Krauze quien manifestó de manera más clara esta posibilidad, pues creyó ver en De la Madrid suficiente vocación democrática y firmeza como para emprender una verdadera democratización política. Además, la insistencia de sus ofrecimientos en ese sentido así lo sugieren. ${ }^{28}$ También Madero consideró la posibilidad de que Díaz tuviera en sus últimos años la visión política suficiente como para dar paso a la democracia en México. Además, él había hecho declaraciones en relación a ello poco antes, en la famosa entrevista con el periodista norteamericano Creelman. Madero expresaba esa esperanza como sigue:

...hasta ahora hemos hablado del general Díaz por los hechos que le conocemos, pero ¿quién nos asegura que este hombre, que ha demostrado ser un hombre extraordinario, no vaya a consumar la carrera con una acción magnánima y generosa que lo pondría en primera línea entre los grandes hombres, no solamente de la patria, sino de la humanidad?29

${ }^{28}$ Op. cit.

${ }^{29}$ La sucesión..., op. cit., p. 31. 
La especulación de Krauze se halló básicamente aislada entre los observadores de la política mexicana, quienes en su mayoría expresaron su escepticismo acerca de la vocación democrática del Presidente, y en general de la élite política. ${ }^{30}$ También en el libro de Madero prevalece el escepticismo acerca de esa voluntad en Díaz, no obstante haber considerado una remota posibilidad en sentido contrario, "El general Díaz, - afirma Madero- acostumbrado a mandar, difícilmente se resolverá a dejar de hacerlo". ${ }^{31}$

No es, por otro lado, sólo cuestión de la voluntad presidencial el que se emprenda una reforma democrática desde arriba, a pesar de la gran importancia que puede tener, pues también debe considerarse la oposición del resto de la élite política, que se beneficia con el sistema, para que dicho proceso sea puesto en marcha. Octavio Paz, por ejemplo, ha sugerido que precisamente las élites política y burocrática, que han tenido un peso fundamental en la estabilidad y en el cambio social, constituyen un fuerte obstáculo a la democracia, debido a los grandes privilegios que han obtenido dentro del autoritarismo. ${ }^{32}$ Madero veía el mismo problema para una democratización desde arriba, pues señalaba que quienes se benefician del régimen absoluto constituyen una gran fuerza que le da continuidad. ${ }^{33}$

Este escepticismo respecto da la voluntad política de la élite para el cambio, quedó confirmado en el caso del régimen porfirista, y parece ser también la conclusión de la oposición democrática de nuestra época, después de haber atestiguado los resultados de diversas sesiones electorales a lo largo del sexenio delamadridista, como los de 1985, que el Presidente ofreció serían las más limpias de la historia; pero sobre todo las de julio de 1986 en varios Estados de la República y en particular en Chihuahua, en donde el fraude en gran escala llevado a cabo por el partido oficial decepcionó profundamente a la ciudadanía respecto de las 1984.

30 Cfr. Valle, Eduardo, "Una crítica escéptica". Vuelta No. 90, mayo de

${ }^{31}$ La sucesión..., op. cit., p. 31.

32 Op. cit.

33 La sucesión..., op. cit., p. 177. 
64 José Antonio Crespo

promesas que tan insistentemente había recibido por parte del Presidente De la Madrid, de que su voto sería respetado. Un ambiente semejante parece reflejar el documento de Madero en 1908, ante las promesas democráticas expresadas por Díaz a Creelman, y su postura real frente a los procesos electorales de la época:

Si estas declaraciones hubieran sido sinceras, ya era tiempo de que hubiera permitido que en los estados y en los municipios se efectuaran elecciones libres, pero hemos visto lo contrario, pues precisamente en este mes (diciembre) se organizaron los demócratas del distrito del centro de este estado (Coahuila), y se propusieron concurrir a las urnas electorales, pero fueron burlados en sus esperanzas por el gobierno que cometió toda clase de irregularidades y atropellos para falsear el voto público. ${ }^{34}$

Indudablemente que la conducta de los porfiristas y de los priístas en cuestión electoral resulta muy semejante, y también por tanto, la exasperación de los disidentes en un régimen y otro, ante la insistencia de imponer a los candidatos oficiales, pese a toda manifestación ciudadana en contra. Y muy parecidos los efectos en términos de legitimidad y credibilidad del régimen, cuyo nivel ha descendido estrepitosamente en el gobierno actual, como descendió en los últimos años del porfiriato

\section{Participación ciudadana y cultura política}

Ante la dificultad de que la reforma democrática provenga de arriba, la oposición democrática se plantea la necesidad de una movilización ciudadana desde abajo para exigir la democracia y presionar a la élite política para que ceda. Una buena parte del debate se concentra en la discusión de este requerimiento, pues se dice que no pude haber democracia auténtica si el proceso de transición no conlleva alguna forma de participación ciudadana, independiente * desde luego de la acción del Estado. Tal era precisamente el principal objetivo del libro de Madero: exhortar a la ciuda-

34 Ibid., p. $\$ 10$. 
danía a organizarse para exigir al régimen la instauración de la democracia; todo dentro de los cauces legales. Sin participación ciudadana, sostenía Madero, no puede concertarse la democracia genuina, sobre todo partiendo de la probable negativa de la élite política a respetar la Constitución. Después de observar la conducta del gobierno en relación al respeto de la voluntad popular, dice Madero: “...comprendí que los que deseábamos un cambio en el sentido que se respetara nuestra Constitución, y que ésta fuera un hecho, nada debíamos esperar de arriba y no deberíamos confiar sino en nuestros propios esfuerzos." 35

Sin embargo en el el debate contemporáneo se reconoce que la cultura política de los mexicanos no es precisamente adecuada para la movilización y participación democrática, sino que más bien predominan rasgos de apatía, inmovilidad y sumisión, en parte resultado de las instituciones autoritarias que, salvo en periodos sumamente reducidos, han prevalecido durante nuestra historia antes y después de la Independencia. Aún más, ese tipo de cultura política apoya y refuerza al autoritarismo, y pone en duda la viabilidad de la democracia en México. ${ }^{36}$ Madero era consciente de ese problema, y reconocía en él un fuerte obstáculo para emprender el movimiento en pro de la democracia:

La razón nos revela las insuperables dificultades que existen para intentar en el terreno de la democracia una lucha fructuosa entre el pueblo adormecido, olvidado de sus derechos, y sin fuerza ni deseos para reconquistarlos. ${ }^{37}$

La estabilidad propiciada por un régimen político en un país tradicionalmente turbulento, confiere a ésta un valor tan especial para la ciudadanía que gran parte de ella está dispuesta a renunciar a la democracia con tal de mantener la paz social. El PRI ha explotado esta situación y destaca continuamente dentro de su discurso la paz social

35 Ibid., p. 20.

${ }^{36}$ Cfr. Paz, Octavio, op. cit.; Meyer, "La democracia política...", op. cit., y Gilly, Adolfo, "La larga travesia", Nexos No. 91, julio de 1985.

${ }^{37}$ La sucesión..., op. cit., p. 263. 
que su régimen ha propiciado. Al mismo tiempo, diversos sectores están dispuestos a prescindir de la democracia siempre y cuando existan las posibilidades de beneficiarse del desarrollo económico, en alguna medida. De ahí que la industralización pueda erigirse como fuente de legitimidad, en sustitución de los principios democráticos, como se dijo antes. Madero señaló en su época un fenómeno semejante:

La Nación, cansada de tantas revueltas y habiendo empezado a gustar del bienestar que trae la paz, se adormeció ante el atronador ruido de los ferrocarriles, de las industrias, de la actividad comercial [...] todos pensaron en enriquecerse; poquísimos se preocupaban de sus derechos políticos. ${ }^{38}$

La imposibilidad de ejercer alguna acción efectiva para evitar el abuso del poder, lleva a la ciudadanía a la resignación y a la indiferencia frente al poder, actitudes que llegan a arraigarse en las conciencias individuales y tienen efectos decisivos en los procesos políticos. El abstencionismo electoral, tanto por desinterés como por protesta, constituye un rasgo típico de una cultura política autoritaria. Madero, refiriéndose a las acciones arbitrarias de los gobernantes porfiristas, señala que:

Al principio la opinión pública protestaba contra ellas, pero cansada de tanto esfuerzo estéril, dejó de protestar y se acostumbró a dominar su indignación, logrando al fin ver como cosas normales los abusos de las autoridades [...El pueblo] se acostumbra a no apreciar el imperio de la ley; sólo obedece servilmente al principio de autoridad, y se acostumbra al disimulo, amoldándose en todo al medio en que se encuentra. ${ }^{39}$

Asimismo, el hecho de que en un sistema autoritario exista siempre el riesgo de sufrir el abuso o la represión por parte de las autoridades, provoca en la mayoría de los ciudadanos el temor a enfrentarse al régimen, lo cual es evidentemente conveniente para la continuidad del mismo. Por lo cual dice Madero:

38 Ibid., pp. 129 y 137.

s9 Ibid., pp. 171 y 218 . 
...ahora lo único que se pretende es evitar que esos abusos recaigan sobre uno mismo, para lo cual se procura estar bien con la autoridad; esa conducta es la que observa la mayoría, generalmente acomodaticia, que quiere vivir tranquila, que sólo se preocupa de sus bienes materiales, del progreso de sus negocios. ${ }^{40}$

Igualmente la influencia que puede llegar a tener el discurso público, cuando éste tiene vigencia, contribuye en mucho a la aceptación del régimen por parte de la ciudadanía, aún cuando se reconozca que buena parte de ese discurso es demagógico, al grado que "...el lenguaje convencional y falso que se emplea en las esferas oficiales, llega a ser el corriente en toda una nación." 41 Las clases humildes, por otro lado, debido a su ignorancia y miseria, son presa fácil de la manipulación gubernamental, que es, según Madero:

...indirectamente mayor sobre las masas, porque los grandes capitalistas generalmente son partidarios del gobierno constituido y ocupan muchos obreros en sus talleres y jornaleros en sus haciendas, a los que fácilmente obligan a votar en favor de las candidaturas oficiales. ${ }^{42}$

Panorama éste indiscutiblemente parecido al de nuestra actualidad, aunque ciertamente con las variaciones derivadas de la distinta circunstancia histórica. Ante la dificultad que representa una cultura política fundamentalmente autoritaria para el desarrollo de la democracia, se podría pensar que efectivamente no queda más remedio a la Nación Mexicana que resignarse a tener por lo pronto un régimen autoritario, como lo sostienen algunos priístas io mismo que lo hacían algunos porfiristas, aunque no públicamente, desde luego. Pero Madero, lo mismo que los demócratas de hoy, mantiene la postura de que la cultura política autoritaria se debe en buena parte a las prácticas e instituciones autoritarias, y por ello al cambiar éstas por unas genuinamente democráticas, poco a poco la cultura mexicana irá tornándose en democrática, con lo que se po-

40 Ibid., p. 171, subrayado en el original.

41 Ibid., p. 165.

12 Ibid., p. 269. 
drá consolidar este tipo de sistema. ${ }^{43}$ Señala Madero al respecto:

...algunos publicistas ya no se toman la molestia de disfrazar su pensamiento y nos dicen con ruda franqueza: "Aún no estamos aptos para la democracia, necesitamos una mano de hierro que nos gobierne" [...] En efecto, la contestación a esa afirmación es muy sencilla: admitiendo por un momento que no estamos aptos para la democracia, ¿de qué manera lograremos llegar a familiarizarnos con sus prácticas si nunca se nos deja practicarlas? La base de prácticas democráticas, que es la consagrada por la costumbre, implica desde luego la teoría puesta en acción, y mientras esto no suceda, mientras los pueblos no lleven a la práctica los ideales democráticos, nunca se familiarizarán con ellos. ${ }^{44}$

Evidentemente el cambio no es considerado automático, como lo pensaron muchos liberales del siglo XIX. La cultura cambia muy lentamente y con mucha dificultad; pero cambia. Aunque para ello se requiere, entre otras cosas, una modificación de las prácticas e instituciones, al menos en un grado en que resulten operativas para un país determinado. Tanto en Madero como en los demócratas de la actualidad se encuentra la postura de que ese intento no tiene por qué postergarse, pese al esfuerzo que suponga. Sostiene Madero:

Todo es pues cuestión de costumbres, pero costumbres que han echado tan hondas raíces en el suelo nacianal, que no podrán desarraigarse sin causar en este profundas alteraciones; sin demandar esfuerzos gigantescos, sin necesitar de la abnegada cooperación de todos los buenos mexicanos. ${ }^{45}$

Por otro lado, no se trata solamente de que se considere que el momento para instaurar la democracia haya llegado, sino que se piensa que de no llevarse a cabo en el presente, la dificultad para intentar el cambio después será mayor, pues, según señala Madero, “...el poco espíritu público que

${ }^{43}$ Cfr. Castañeda, Jorge, "México, el desafío democrático". Nexos No. 105, septiembre de 1986.

45 Ibid., p. 31. 
aún se nota acabará por desaparecer y cada vez estaremos menos aptos para la democracia". ${ }^{46}$ De ahí el temor que tenía Madero acerca de la institucionalización del autoritarismo, pues comprendía que la mayor fuerza de éste dificultaría la transición a la democracia, por lo que los vicios de la cultura autoritaria arraigarían en la conciencia nacional de manera irreversible, causando por supuesto todo tipo de problemas para la buena marcha de la nación:

...que se prolongue este régimen, y toda idea de patriotismo desaparecerá por completo y la mayor corrupción en las costumbres acabará de matar cuanto sentimiento noble y generoso abrigan aún los pechos mexicanos. La decadencia será cada vez mayor, y México, que necesita ser nación fuerte para el cumplimiento de sus grandes destinos, tendrá que resignarse a sucumbir bajo el peor de sus vicios... ${ }^{47}$

A partir de esta advertencia, Madero pensaría que no hay de qué extrañarse por la situación que atraviesa el país en la actualidad, ya que la consideraría, como muchos de los demócratas modernos, una derivación lógica de la institucionalización del autoritarismo de la que nos prevenía. Pese a todo, los demócratas contemporáneos guardan todavía la esperanza de que las cosas puedan cambiar, de lograrse llevar a cabo la democratización política. Pero como Madero, opinan que el momento para hacerlo es impostergable, pues de lo contrario las cosas cambiarán de cualquier modo, pero para peor. ${ }^{48}$ De ahí el tono impaciente del llamado de Madero a la democracia, que recuerda el que ahora hace la oposición democrática de nuestro tiempo.

\section{El proceso de transición a la democracia}

En el análisis especulativo sobre la democracia, se toca también el punto de cómo podría llevarse a cabo el proceso de transición dentro del marco de las instituciones vigentes.

46 Ibid., p. 256.

47 Ibid., p. 306.

${ }^{48}$ Cfr. González Casanova, Pablo, "La democracia en tiempos de crisis", en Varios, Las elecciones en México: Evolución y perspectivas, México, Siglo XXI, 1985. 
Prevalece la postura de que lo más conveniente para el país es que se llevase a cabo, en caso de darse, de manera pacífica y dentro del marco legal. Es pues, una posición legalista com's lo era la de Madero en 1908. Si acaso sólo algunos seciores de la izquierda radical contemplan la posibilidad Se que el cambio podrá sobrevenir como consecuencia de una revolución armada. ${ }^{49}$ Pero el resto de la oposición mantiene una posición legalista. De hecho, como se dijo antes, lo que exige al gobierno es su apego a la Constitución, tal como lo hacía Madero.

En efecto, Madero desconfiaba de los movimientos revolucionarios por muchas razones. En primer lugar, éstos representaban una guerra fratricida que costaría al país numerosas vidas, así como destrucción y retroceso económico. Además, implicaría destruir el orden institucional que con mucha dificultad había logrado imponer la paz social. Por ello decía:

...si aconsejamos que se desprecie la vida, para salvar a la patria, no por eso aconsejamos que se tomen las armas para combatir el actual gobierno, pues volveríamos a caer en el tristísimo dédalo de las guerras intestinas, que tantos peligros acarrearían a la patria. ${ }^{50}$

Además, el análisis de las revoluciones ocurridas hasta su época, le llevó a la conclusión de que éstas normalmente terminan en un sistema altamente centralizado, principio prácticamente consagrado por la sociología contemporánea de las revoluciones sociales.

...por amarga experiencia sabemos los mexicanos que siempre que hemos empuñado las armas para derrocar algún mal gobierno, hemos sido cruelmente decepcionados por nuestros caudillos que nunca nos han cumplido las promesas que nos hicieron [...pues] una vez obtenido el triunfo, se sienten embriagados por la victoria y mareados por la adula1 ón, y olvidan las promesas que hicieron a la patria, y olvidan que sus éxitos los debieron a la fuerza de los princi-

49 , ir. Valle, Eduardo, op. cit.

${ }^{50}$ La sucesión..., op. cit., p. 259. 
pios que proclamaban; a la fuerza de la opinión pública y a la ayuda del pueblo. ${ }^{51}$

El que Madero pensara así explica su conducta posterior cuando triunfó la revolución sobre Díaz, de licenciar las tropas revolucionarias en lugar de desmantelar al ejército porfirista. Creía más peligrosos a los revolucionarios, pues se sentirían con derecho a reclamar a la patria sus servicios a costa de la democracia, como habían hecho los porfiristas en su momento. De cualquier forma, Madero intentó en 1908 poner en marcha la transición democrática dentro de la ley, y de manera pacífica. No desconocía la posibilidad de que surgiera un movimiento armado, de cerrarse la élite porfirista a la razón y a las necesidades del momento. Mas consideraba esta hipótesis como "... la menos problable". ${ }^{52}$ Pensaba, contrariamente a las tesis marxistas de la época, que "...los pueblos cuanto más se civilizan más huyen de las revoluciones, y prefieren soportar un gobierno relativamente malo que sufrir las desastrosas consecuencias de una revolución". ${ }^{53}$

Evidentemente, México en 1910, pese al nivel de civilización relativa que había alcanzado en los últimos años, no se encontraba en la situación señalada por Madero, en donde una revolución social tiene pocas probabilidad de surgir. Pero el México contemporáneo sí ha alcanzado ya un grado de modernización en que las revoluciones sociales difícilmente se dan, de tal manera que casi nadie considera seriamente la posibilidad de un movimiento de ese tipo en nuestros días, salvo tal vez algunos grupúsculos ubicados dentro de la ortodoxia marxista. Por lo cual la gran mayoría de la oposición democrática busca el cambio dentro de las leyes. La violencia no está ciertamente descartada como posibilidad, pero sí como estrategia. Señala al respecto Soledad Loaeza que podría darse el caso de que, ante la cerrazón del gobierno en materia electoral, se registraran hechos de violencia, como de hecho ha sucedido en algunos municipios "...de manera que el proyecto de democracia otorga-

51 Ibid., pp. 299 y 117.

52 Ibid., p. 298.

53 Ibid., p. 121. 
da amenaza convertirse en democracia arrebatada." 54 De cualquier forma existe una política muy clara de los partidos de oposición para mantenerse dentro de la legalidad. Por ejemplo, ante las irregularidades de las elecciones de julio en Chihuahua, los panistas han expresado sus protestas siguiendo la estrategia de desobediencia civil no violenta. Así, la alternativa violenta parece vedada a la oposición actual.

Otro de los puntos de la discusión acerca de la forma de transición democrática, se refiere al aprovechamiento de la estabilidad lograda por el régimen. Madero pensaba que al hacerse el cambio dentro del orden vigente, se tendrian mayores posibilidades de fortalecer el nuevo régimen democrático, pues éste sería heredero de la fuerza relativa alcanzada por el Porfiriato. Así, si bien temía la sucesión de Díaz a través del autoritarismo, por ser esto un paso hacia su institucionalización, de igual manera la sucesión por vías democráticas representaría un elemento fundamental de la institucionalización democrática, pues, de esa forma, “...estaría asegurado el régimen constitucional y la paz, definitivamente consolidada, puesto que las energías nacionales habrían encontrado su cauce natural. " 55 Es por ello, probablemente, que intentó mantener la estructura porfirista después del triunfo de su levantamiento armado. No deseaba una revolución, como se dijo antes, pero no contó con que una vez iniciada ésta, el peligro de la contrarrevolución era mayor que el de la radicalización del movimiento. Intentó con esa política evitar la inestabilidad que sobrevenía a los movimientos armados, pero ese paso estaba dado y no podía haber reversión al respecto.

Por otro lado Madero sotenía que la reforma dentro de la legalidad permitiria un cambio gradual pero firme, de tal forma que no se resintiera el sistema y mantuviera su estabilidad. Las libertades democráticas, por tanto, podrían concederse de la base a la cúspide, es decir desde el nivel municipal, al estatal y al federal. ${ }^{56}$

54 "El llamado a las urnas. ¿Para qué sirven las elecciones en México". Nexos No. 90, junio de 1985.

${ }^{55}$ La sucesión..., op. cit., p. 295.

56 Ibid., p. 293. 
Esta propuesta es semejante a aquella que algunos autores contemporáneos han hecho recientemente. Molinar sugiere, por ejemplo, que las elecciones libres harian perder al PRI el dominio absoluto que goza, pero no la hegemonía, modificando nuestro sistema de partidos, de único a dominante, lo que permite una transición paulatina a la democracia genuina. ${ }^{57}$ Por su lado, Gabriel Zaid expuso una forma en que podría modificarse el sistema político hacia la democracia, imponiendo la libertad electoral de la periferia al centro, es decir, primero en los Estados y después en el Congreso de la Unión, de manera parecida a lo propuesto por Madero. Señala Zaid al respecto;

Bastarían unas cuantas gubernaturas reconocidas a la oposición para que la reacción en cadena fuera incontenible, para dar esperanzas y reanimar decisivamente a toda la sociedad, para desencadenar la madurez política del país. ${ }^{58}$

La respuesta a las posturas reformistas de Madero y de la oposición democrática actual fue la misma: la conservación del poder en todos los niveles al precio que fuera. Tal vez la idea de que cediendo el poder en niveles estatales se podría desencadenar la democracia, influyó en el gobierno para evitar a toda costa que eso sucediera, precisamente, porque lo que menos desea es la democratización, tanto en el caso de Díaz como en el del PRI. Madero advirtió los disturbios que ello podría ocasionar, y ahora se oyen voces en el mismo sentido, como en el caso de Paz: "O damos un paso definitivo hacia la democracia o la Nación se estanca [...y] El estancamiento no sólo es inmovilidad sino acumulación de problemas, conflictos y agravios, es decir, a la larga, convulsiones y estallidos." 59

No violencia revolucionaria, como se dijo antes, pero sí violencia social, que lejos de resolver la crisis actual sólo la complicaría. La demanda por democracia se presenta 1985.

${ }^{57}$ Molinar, Juan, “Un sistema de partido y medio", Nexos No. 87, marzo de

58 "Escenarios sobre el fin del PRI", en Vuelta No. 103, junio de 1985.

59 Op. cit. 
como urgente ahora, del mismo modo que se hacía en 1908. Y la estrategia diseñada en estos días por la oposición democrática, sigue pautas parecidas a las que Madero y otros antirreleccionistas pensaron en su época: organizar un movimiento a nivel nacional, para exhortar a la ciudadanía a exigir la democracia política y el respeto al voto. En 1908 , Madero proponía la organización de ese movimiento a través del Partido Nacional Democrático, que daría entrada a todos los que desearan la democracia genuina, por encima de otras diferencias programáticas e ideológicas. ${ }^{60}$ La oposición actual ha organizado recientemente un Foro Nacional por el Sufragio Efectivo, cuyos objetivos se asemejan a los del Partido Nacional Democrático de Madero. La Declaración del Foro expresa lo siguiente:

Convocamos a los ciudadanos a participar en el esfucreo de abrir cauces a la democracia política. El malestar colectivo está a la vista, ya se exprese como voto a la oposición, indignaciones y quejas, creencias en el rumor o abstención (lectoral. Es tiempo todavía de evitar las explosiones que produce la cerrazón política; pero al respecto hay una consideración moral e histórica todavía más alta: el sufragio efectivo es reclamo de justicia social de los mexicanos. ${ }^{61}$

El Foro Nacional, como el Partido Nacional Democrático, acepta en su seno partidos y organizaciones cívicas de distinta orientación ideológica, vinculados por un objetivo común: la demanda por democracia política. Su estrategia: recorrer el país "...movilizando al pueblo para instaurar un sistema político democrático". ${ }^{62}$ Los rasgos, argumentos y estrategias de los opositores y disidentes al régimen priísta, asumen por tanto un extraordinario paralelismo con el movimiento de oposición que dio lugar al derrocamiento del régimen de Díaz, a principios de este siglo.

${ }^{60}$ La sucesión..., op. cit., p. 280.

61 En Proceso No. 515, 15 de septiembre de 1986.

62 Ibid. 


\section{Consideraciones finales}

Todo hace concluir que los ataques lanzados al régimen porfirista y al régimen prísta por sus respectivos disidentes son de una similitud tal, que no dejan de sugerir que su surgimiento responde a una semejanza esencial entre ambos regímenes. Los dos se originaron de movimientos armados, enarbolando la bandera democrática: Los dos se instituyeron después con formalidad democrática y prácticas autoritarias. Ambos han seguido una política de desarrollo económico a través del privilegio y en medio de una gran injusticia social. En los dos se ha dado un alto nivel de corrupción, influyentismo e irresponsabilidad pública. Por (llo, estos dos regímenes han generado una crítica en su contra muy parecida. Sobre todo porque la denuncia que Madero expresó en 1908 y las críticas que hace la oposición de los años recientes reflejan un momento en que la legitimidad y la credibilidad del régimen respectivo se encuentra en su nivel más bajo, desde que fue instaurado.

En el pensamiento de Madero parece redescubrirse la exasperación de los demócratas y el cinismo de los gobernantess de nuestro tiempo, en medio de un sistema agotado y desacreditado. El siguiente párrafo escrito por Madero sintetiza el diálogo entre porfiristas y demócratas de principios de siglo:

México pasa por uno de los periodos de su historia más peligrosos, y sólo el patriotismo de todos los mexicanos podrá salvarlo de las tempestades que lo amenazan.

Pero la palabra patriotismo ha sido corrompida como todo lo demás. Ya nadie la interpreta en su verdadero sentido, sino que la adulteran para servirse de ella según su conveniencia, así como hacen con todas las leyes.

Nosostros decimos: en este caso el patriotismo debía consistir en que cada quien sacrificara sus ambiciones personales y procurara amoldar todos sus actos a la ley, respetando nuestra sabia Constitución, rindiendo culto a la libertad nacional libremente manifestada. 
Los aduladores del general Díaz nos dicen: El patriotismo en las actuales circunstancias consiste en reelegir al hombre extraordinario que por más de 30 años ha llevado con gran acierto las riendas del gobierno; sólo él será capaz de llevar a la Nación a sus grandes destinos; dejémoslo que corone su obra.

Muy bien, decimos nosotros, no nos oponemos a que siga el general Díaz en el poder, si tal es la voluntad de la Nación; pero que se deje a ésta el medio de manifestarla libremente.

A esto contestan que siempre se ha dejado a la Nación en absoluta libertad, que el jefe de Estado siempre ha rendido culto a la Constitución, que ha sido el infatigable sostén de la ley.

Con eso nos quitan todo argumento, pues nos hablan en un idioma que no es el nuestro. Nosotros empleamos el de la verdad y nuestros adversarios el convencional tan en boga en estos tiempos, en que todo el mundo sabe representar tan bien su papel. Con este motivo desconfiamos de todo lo que nos había dicho nuestro interlocutor, hasta lo referente al coronamiento de la obra del general Díaz, pues si por eso debemos entender que va a coronar su obra devolviéndonos nuestras libertades, no sabemos por qué no lo habrá empezado a hacer poco a poco, [...] en cambio si por coronamiento de su obra, debemos entender la implantación definitiva del centralismo y el absolutismo, entonces sí comprendemos muy bien, pero no estamos de acuerdo en que se lleve adelante tal coronamiento y nos opondremos a ello dentro de la ley, hasta donde nos alcancen nuestras fuerzas. ${ }^{63}$

Cámbiese al dictador por el partido, y el diálogo resulta ser de una vigencia sorprendente en nuestros días. No es esta, ciertamente, una pequeña diferencia, pues representa la modernización y flexibilidad del régimen priísta en relación al porfirista. Y gracias a ello el primero ha tenido mayor fuerza y continuidad. Y por ello también su derrocamiento por la fuerza se vislumbra como sumamente improbable. Pero esto nos lleva a la conclusión de que, para infortunio de Madero, el movimiento iniciado por él para

${ }^{63}$ La sucesión..., op. cit., p. 255. 
derrocar a la dictadura porfirista dio lugar a un régimen más fuerte y flexible pero en esencia similar; un Porfiriato modernizado, pero no menos autoritario. Es la paradoja de nuestra historia contemporánea, señalada por Edmundo $O^{\prime}$ Gorman: la única bandera que daba sentido histốrico a la revolución mexicana, fue inmediatamente enterrada por el régimen que de ahí surgió, para continuar con nuevos bríos la política iniciada por el Porfiriato. ${ }^{64}$

Finalmente, cabe aclarar que del paralelismo aquí sugerido entre el tono del discruso de oposición en los años finales del Porfiriato, y el de la oposición contemporánea, no debe desprenderse que el régimen actual se encuentre en su etapa final. Las diferencias entre el régimen priísta y el porfirista son las súficientes como para pensar que aquél pueda ser derrocado. En todo caso, lo más que se puede decir es que la viabilidad del actual sistema político empieza a ponerse en entredicho. Tal vez las presiones puedan llegar a ser lo suficientemente fuertes como para que en un futuro no lejano la élite política se decida a aceptar las reformas democráticas. $O$ en caso de darse un empecinamiento en conservar el poder absoluto por parte de los priístas, quizá el Estado Mexicano no pueda mantener sus características actuales, y se torne en uno más represivo, apoyado por círculos sociales más estrechos, como numerosos autores lo han destacado. De cualquier manera la evidente pérdida de credibilidad del régimen priísta, constituye un resorte para impulsarlo a un cambio, sea cual fuere la dirección que éste tome. Que el cambio se haga en sentido democrático dependerá en gran parte de la oportunidad con que se ponga en marcha.

${ }^{64}$ México; el trauma de su historia, México, UNAM, 1977. 